\title{
Toxicity assessment of flavour chemicals used in e-cigarettes: current state and future challenges
}

\author{
Sophia Barhdadi ${ }^{1}$ (D) $\cdot$ Vera Rogiers $^{2} \cdot$ Eric Deconinck $^{1} \cdot$ Tamara Vanhaecke $^{2}$
}

Received: 5 May 2021 / Accepted: 17 May 2021 / Published online: 22 May 2021

(c) Crown 2021

Since its introduction more than a decade ago, the e-cigarette has gained an enormous popularity. One of the main reasons for the ever increasing attractiveness is its availability in many different flavours (Bals et al. 2019). In 2007, more than 7000 flavours were used in e-cigarettes (Zhu et al. 2014). However, intentional inhalation of chemicals via e-cigarettes appears to be not without risks, as shown in 2019 in the US by the outbreak of several cases of e-cigarette or vaping product use-associated lung injury (EVALI) (Boudi et al. 2019), suspected to be linked to the presence of vitamin-E acetate, a common nutrient found in most foods.

The majority of the flavourings present in e-liquids are food-grade, meaning that they are assessed and permitted for oral use. These flavourings acquired the 'generally recognised as safe' (GRAS) status from the US Flavour and Extract Manufacturers Association (FEMA). In Europe, the European Food Safety Authority (EFSA) is responsible for the assessment of food chemicals. Regardless of their approved use in food products, the inhalation safety of these GRAS flavours is, however, not assured (Leigh et al. 2016). In addition, besides using known food flavourings, also the natural extracts such as tobacco extracts, essential oils, herbal extracts, or non-chemically synthetized flavourings may be present in e-liquids. The composition of these extracts is often not well-known and may vary from batch to batch depending on biological and geographical origins

Eric Deconinck and Tamara Vanhaecke are equally contributing senior authors

Sophia Barhdadi

sophia.barhdadi@sciensano.be

1 Sciensano, Medicines and Health Products, Scientific Direction of Chemical and Physical Health Risks, Rue Juliette Wytsmanstraat 14, 1050 Brussels, Belgium

2 Department of In Vitro Toxicology and Dermato-Cosmetology (IVTD), Faculty of Medicines and Pharmacy, Vrije Universiteit Brussel (VUB), Laarbeeklaan 103, 1090 Brussels, Belgium
(Bhattacharya 2016). It is thus highly likely that e-liquids and/or e-cigarette emissions contain substances with unknown toxicological properties or known toxic components that exceed certain limits and thus might cause acute and/or chronic adverse human health effects. Therefore, it is necessary to investigate potential health risks associated with the inhalation of flavouring substances.

Considering the very large number of flavourings used in e-liquids, evaluation of the safety of each of these via the inhalation route is challenging. Only very limited information is currently available on e-liquid toxicity. Indeed, studies have hitherto mainly focussed on in vitro cytotoxicity testing (e.g. high throughput cell viability assays using HEK239T cells) in which the e-liquid is tested as a complete mixture of different aromas in combination with the solvents propylene glycol and glycerol (Sassano et al. 2018; Hua et al. 2019; Omaiye et al. 2020).

Even more challenging is the identification and evaluation of the chemicals that are present in the produced e-cigarette aerosol emissions (heating- and interaction products). Indeed, only a few studies focus on heating products of flavoured e-cigarettes. In this context, Khlystov and Samburova found a correlation between the formation of toxic aldehydes and the amount of flavourings in e-liquids (Khlystov and Samburova 2016). However, these controversial results have yet to be confirmed by other studies. In addition to heating products, interaction products can also be present in the aerosol emissions due to reactions between different aromas present in the e-liquid mixture. As such, the formation of aldehyde-propylene glycol acetal adducts have been described to be formed in e-liquid matrices containing aromas, including benzaldehyde, cinnamaldehyde, citral, ethyl vanillin and vanillin (Erythropel et al. 2018).

Obviously, the lack of toxicological information urges the in-depth analysis of e-cigarette aerosols, including their generated heating/interaction products. At least the following toxicological endpoints should get more attention: 
Genotoxicity/carcinogenicity: recent studies have shown that e-liquids may contain genotoxic components such as safrole, estragole, 2-furyl methyl ketone, dimethylhydroxyfuranone and pulegone (Jabba and Jordt 2019; Barhdadi et al. 2021). Yet, according to the EU Tobacco Product Directive 2014/40/EU, all substances with Carcinogenic, Mutagenic or Reprotoxic (CMR) properties are not authorised in e-liquids irrespective of their presence in the aerosols. For a number of flavourings, evaluations are already available with respect to genotoxic and carcinogenic characteristics, in particular in EFSA opinions. These could be taken as a basis for the CMR assessment of e-liquid flavourings.

Inhalation toxicity: inherent to the use of e-cigarettes, flavouring compounds present in the e-liquids might lead to local respiratory toxicity (Sassano et al. 2018). Especially, flavourings from the aldehyde groups are known as local irritants of the respiratory tract (Tierney et al. 2015). However, the toxicity (both local and systemic) of chemicals through inhalation after acute and/or chronic exposure has not been studied as extensively as via the oral or dermal route. Examples of inhalation toxicants have mainly been discovered in retrospective studies of pathologies observed in workers upon chronic exposure to flavouring chemicals during their work activity. The best-known example of flavourings that are safe for oral use, but cause local lung inflammation after acute and chronic exposure are the diketones diacetyl and acetylpropionyl (Brass and Palmer 2017).

Respiratory sensitization: besides local lung inflammation, respiratory sensitization is yet another toxicological endpoint that is currently not given much attention in e-cigarette research, despite reported cases of allergic reactions occurring in the lungs after e-cigarette use (Azevedo et al. 2019). Some chemicals present in e-liquids such as methyl cyclopentenolone and $\alpha$-ionone have a GHS classification as inhalation allergen (H334) (Girvalaki et al. 2018). A study by the Dutch National Institute for Public Health and the Environment (NHIPHE) has also shown that isoeugenol, a known skin sensitizing fragrance, can lead to adverse effects of the respiratory immune system when inhaled (Ter Burg et al. 2014). It can be expected that other skin sensitizers, known to cause type IV-delayed cell-mediated hypersensitivity, may also give rise to inhalation sensitization. However, it is unclear whether this applies to all skin allergenic fragrances (Basketter and Kimber 2015).

In summary, there are indications that a number of flavourings that have been cleared in terms of safety for oral consumption are potentially toxic when inhaled via e-cigarette vaping. A comprehensive safety evaluation for each of these flavourings and combinations thereof for at least the above-listed toxicological endpoints is urgently needed to better regulate these compounds and, if necessary, restrict their use by setting limit values. Yet, to do so, additional information of realistic exposure scenarios for the different e-cigarette devices is also required. As mentioned in a previous editorial, a multidisciplinary approach will be necessary to tackle these challenges that are associated with the assessment and management of risks of e-cigarettes products (Bolt 2020).

\section{Declarations}

Conflict of interest The authors declare that they have no conflict of interest.

\section{References}

Azevedo A, Lobo I, Selores M (2019) Allergic contact dermatitis and electronic cigarettes: Is nickel to blame? Contact Dermatitis 81:135-136. https://doi.org/10.1111/cod.13257

Bals R, Boyd J, Esposito S et al (2019) Electronic cigarettes: a task force report from the European Respiratory Society. Eur Respir J 53:1-24. https://doi.org/10.1183/13993003.01151-2018

Barhdadi S, Mertens B, Anthonissen R et al (2021) Identification of flavouring substances of genotoxic concern present in e-cigarette refills. Food Chem Toxicol. https://doi.org/10.1016/j.fct.2020. 111864

Basketter D, Kimber I (2015) Fragrance sensitisers: Is inhalation an allergy risk? Regul Toxicol Pharmacol 73:897-902. https://doi. org/10.1016/j.yrtph.2015.09.031

Bhattacharya S (2016) Chapter 3-cultivation of essential oils. In: Preedy V (ed) Essential oils in food preservation, flavor and safety. Academic Press, San Diego, pp 19-29

Bolt HM (2020) Electronic cigarettes and vaping: toxicological awareness is increasing. Arch Toxicol 94:1783-1785. https://doi.org/10. 1007/s00204-020-02786-3

Boudi FB, Patel S, Boudi A, Chan C (2019) Vitamin E acetate as a plausible cause of acute vaping-related illness. Cureus 11:10-14. https://doi.org/10.7759/cureus.6350

Brass DM, Palmer SM (2017) Models of toxicity of diacetyl and alternative diones. Toxicology 388:15-20. https://doi.org/10.1016/J. TOX.2017.02.011

Erythropel HC, Jabba SV, DeWinter TM et al (2018) Formation of flavorant-propylene glycol adducts with novel toxicological properties in chemically unstable e-cigarette liquids. Nicotine Tob Res 21:1248-1258. https://doi.org/10.1093/ntr/nty192

Girvalaki C, Tzatzarakis M, Kyriakos CN et al (2018) Composition and chemical health hazards of the most common electronic cigarette liquids in nine European countries. Inhal Toxicol. https://doi.org/ $10.1080 / 08958378.2018 .1527879$

Hua M, Omaiye EE, Luo W et al (2019) Identification of cytotoxic flavor chemicals in top-selling electronic cigarette refill fluids. Sci Rep 9:1-15. https://doi.org/10.1038/s41598-019-38978-w

Jabba SV, Jordt SE (2019) Risk analysis for the carcinogen pulegone in mint- and menthol-flavored e-cigarettes and smokeless tobacco products. JAMA Intern Med 179:1721-1723. https://doi.org/10. 1001/jamainternmed.2019.3649

Khlystov A, Samburova V (2016) Flavoring compounds dominate toxic aldehyde production during e-cigarette vaping. Environ Sci Technol 50:13080-13085. https://doi.org/10.1021/acs.est.6b05145

Leigh NJ, Lawton RI, Hershberger PA, Goniewicz ML (2016) Flavourings significantly affect inhalation toxicity of aerosol generated 
from electronic nicotine delivery systems (ENDS). Tob Control 25:ii81-ii87. https://doi.org/10.1136/tobaccocontrol-2016-053205

Omaiye EE, Luo W, Mcwhirter KJ et al (2020) Electronic cigarette refill fluids sold worldwide: flavor chemical composition, toxicity, and hazard analysis. Chem Res Toxicol. https://doi.org/10.1021/ acs.chemrestox.0c00266

Sassano MF, Davis ES, Keating JE et al (2018) Evaluation of e-liquid toxicity using an open-source high-throughput screening assay. PLoS Biol. https://doi.org/10.1371/journal.pbio.2003904

Ter Burg W, Bouma K, Schakel DJ et al (2014) Assessment of the risk of respiratory sensitization from fragrance allergens released by air fresheners. Inhal Toxicol 26:310-318. https://doi.org/10.3109/ 08958378.2014 .888110
Tierney PA, Karpinski CD, Brown JE et al (2015) Flavour chemicals in electronic cigarette fluids. Tob Control 25:e10-e15. https://doi. org/10.1136/tobaccocontrol-2014-052175

Zhu S-H, Sun JY, Bonnevie E et al (2014) Four hundred and sixty brands of e-cigarettes and counting: implications for product regulation. Tob Control 23:iii3-iii9. https://doi.org/10.1136/tobac cocontrol-2014-051670

Publisher's Note Springer Nature remains neutral with regard to jurisdictional claims in published maps and institutional affiliations. 